\title{
Curvilinear Relationship Between Age and Post-Stroke Fatigue among Patients in the Acute Phase following First-Ever Stroke
}

\section{Anners Lerdal ${ }^{1,2 *}$, Caryl L Gay ${ }^{1,3}$ and Kathryn A Lee}

${ }^{1}$ Department of Research, Lovisenberg Diakonale Hospital, Oslo, Norway

${ }^{2}$ Department of Nursing Science, Institute of Health and Society, Faculty of Medicine, University of Oslo, Oslo, Norway

${ }^{3}$ Lovisenberg Diakonale University College, Oslo, Norway

${ }^{4}$ Department of Family Health Care Nursing, University of California, San Francisco, CA, USA

\begin{abstract}
Introduction: Fatigue is a common complaint after stroke and may be assumed to be related to older age. Contradictory findings on the relationship between age and post-stroke fatigue have been reported in the rehabilitation phase, but no studies have described their relationship in the acute phase. The aim of this study was to explore the relationships among fatigue, age, and other socio-demographic and clinical factors during the acute phase following stroke.

Methods: The sample included 115 patients (ages 29 to 91 years) with first-ever stroke admitted to two hospitals in Norway in 2007 and 2008. Data were collected from medical records and face-to-face interviews within 2 weeks of hospital admission. Measures included the Fatigue Severity Scale, SF-36A Physical Functioning Scale, Beck Depression Inventory-II, Barthel Index and Pittsburgh Sleep Quality Index. Pre-stroke fatigue was defined as fatigue lasting longer than three months before the stroke. Analyses included age group comparisons and hierarchical linear regression.

Results: The relationship between age and fatigue was weak and U-shaped rather than linear, with the youngest $(<60$ years) and oldest ( $>75$ years) groups reporting higher levels of post-stroke fatigue. The effect of age on poststroke fatigue remained significant after controlling for gender, work status, pre-stroke fatigue, physical functioning, sleep disturbance, and comorbidity, but was attenuated after controlling for depressive symptoms.

Conclusion: Although post-stroke fatigue in the acute phase was more severe among the youngest and oldest groups, age only explained a small proportion of post-stroke fatigue variability. Clinical factors, such as pre-existing fatigue, physical functioning, and particularly mood are likely more important explanations for post-stroke fatigue than age. Since fatigue may impact the patient's ability to participate in rehabilitation, clinicians should pay attention to fatigue and its co-existing factors during the acute phase. Evidence-based interventions for managing post-stroke fatigue and improving rehabilitation outcomes are warranted.
\end{abstract}

Keywords: Stroke; Fatigue; Age; Rehabilitation; Quality of life; Physical impairment; Depression

\section{Introduction}

Stroke is the most frequent cause of disability in elderly people, and fatigue is one of the most common complaints after stroke [1]. The prevalence of post-stroke fatigue is reported to be between $36-77 \%$ [2-4]. Fatigue can be defined as a sense of exhaustion, lack of energy, or tiredness distinct from sleepiness, sadness or weakness [5-7]. Unlike tiredness, clinically significant fatigue is unrelieved by a night of good quality sleep [5]. It is commonly assumed that older people are generally more affected by fatigue than younger people, yet findings about the relationship between post-stroke fatigue and age are contradictory. A number of studies report no relationship between age and post-stroke fatigue [2,8-13]. In contrast, older age was related to higher fatigue among patients one year after first-ever stroke when sex, depressive symptoms and comorbidity were controlled for in a multivariate analysis [11]. In a recent cohort study of Canadians with a mean age of 68.4 years, younger stroke survivors report more fatigue than older survivors one year post-stroke [14], which supports findings from another recent study [15].

Similar to our previous report [16], several studies demonstrate that post-stroke fatigue is related to pre-stroke fatigue [9], poor physical functioning [9], dependency in activities of daily living [17,18] and depression $[9,13,15]$. Studies report conflicting findings on whether there is a positive association between post-stroke fatigue and sleep quality $[9,19]$ or no relationship at all [11].

In order to develop targeted interventions for post-stroke fatigue, it is clinically important to understand the extent to which fatigue is related to the patient's age or clinical characteristics and comorbidity. To our knowledge, no studies have reported findings on the relationship between age and fatigue in the acute phase after stroke. The aim of this study was to explore the relationship between fatigue and age during the acute phase after stroke while controlling for other socio-demographic and clinical factors, including depression, independence in activities of daily living, sleep quality, and physical functioning.

\section{Method}

\section{Sample and procedures}

As part of the longitudinal Post-stroke Fatigue study in Norway, stroke patients were recruited upon hospital admission between March 2007 and September 2008 at one hospital in the south-eastern region, and between September 2007 and June 2008 at a university hospital in Oslo. Data were collected from medical records and from standardized interviews by three trained interviewers using validated questionnaires.

*Corresponding author: Anners Lerdal, Lovisenberg Diakonale Hospital Lovisenberggt. 17, NO-0440 Oslo, Norway, Tel: +47-23225000; Fax: +4723225023; E-mail: anners.lerdal@medisin.uio.no

Received April 04, 2013; Accepted May 09, 2013; Published May 13, 2013

Citation: Lerdal A, Gay CL, Lee KA (2013) Curvilinear Relationship Between Age and Post-Stroke Fatigue among Patients in the Acute Phase following First-Ever Stroke. Int J Phys Med Rehabil 1: 141. doi:10.4172/2329-9096.1000141

Copyright: $\odot 2013$ Lerdal A, et al. This is an open-access article distributed under the terms of the Creative Commons Attribution License, which permits unrestricted use, distribution, and reproduction in any medium, provided the original author and source are credited. 
Inclusion criteria were that patients had first-ever clinical presentation of stroke according to the ICD-10 (I60 - I64) [20], were 18 years or older, and had satisfactory cognitive functioning to participate. Patients who were fully conscious, or somnolent but could be awakened to full consciousness (equivalent to a score of 4 or 6 on item \#1 in the Scandinavian Stroke Scale-SSS) [21] and oriented for time, place and person (equivalent to a score of 4 on item \#6 in the SSS) were eligible. At one hospital those who did not meet the criteria for cognitive functioning were further assessed with Mini-Mental State Examination (MMSE). Those with an MMSE score $\leq 10$ and those with an MMSE score between 11 and 23 but found cognitively incompetent by a physician or nurse were excluded. At the second hospital patients who did not meet the SSS criteria were clinically assessed by the stroke team. Those found cognitively incompetent were excluded from participation. In addition, patients who were assessed by the recruiting nurses to be unable to communicate (participate in a meaningful conversation with an interviewer or point on the response alternatives on questionnaires) were excluded.

Of the 193 patients diagnosed with first-ever stroke, 14 were excluded due to reduced cognitive functioning, 26 were excluded because of difficulty communicating due to stroke, and one was excluded because of inability to understand Norwegian language. Of the 152 patients eligible to participate, 125 patients consented (82\%) of which six died or were transferred to hospitals in other regions before collecting the first set of data, resulting in a sample of 119 patients (Figure 1). Data from 4 of the 119 patients were collected later than 15 days after admission and were excluded. Therefore 115 patients were included in this analysis of acute phase fatigue experience.

\section{Measurements}

Post-stroke fatigue: The 9-item Fatigue Severity Scale (FSS) [22] is the most commonly used instrument to measure fatigue in stroke and has good validity and reliability [1,23]. The modified FSS-7 was previously shown to have stronger psychometric properties among stroke patients [23] and was therefore used in this study. Patients rate their level of agreement with 7 statements about fatigue interference on a seven-point Likert scale ranging from strongly disagree to strongly agree. An FSS mean score ranging from 1 to 7 was computed for each patient, with higher scores indicating higher levels of fatigue. The FSS score was also categorized into one of three groups; no/mild fatigue (FSS $<4)$, moderate fatigue (FSS $=4-4.9$ ), and severe fatigue (FSS $\geq$ $5)$. Internal consistency of the FSS in the present study was adequate (Cronbach a coefficient $=0.87$ ). Mean FSS scores did not differ by interviewer.

Pre-stroke fatigue: Pre-stroke fatigue was measured retrospectively with two items; "did you experience fatigue before you had your stroke" (yes/no) and if yes, "how long did you experience fatigue" (less than one week, less than three months, 3-6 months and more than 6 months). Patients who reported fatigue lasting longer than three months before the stroke were defined as having pre-stroke fatigue.

Socio-demographic variables: Data on patient age (years), sex, and relationship status (married/living with a partner or not) were collected from their medical record, while data on level of formal education (less than twelve years versus twelve years or more) and employment were collected from the questionnaire. Those in paid work or self-employment were categorized as working, while students, full time homemakers and those on disability or old age pension were categorized as not working.

Stroke characteristics: Based on CT/MRI imaging in the medical record, stroke type was categorized as either infarction or haemorrhage, and stroke location was categorized as left, right or bilateral.

Physical functioning: The level of physical functioning (PF) was self-rated using the 10-item PF subscale from the Short Form-36 Acute version (SF-36A) [24]. The SF-36A is a questionnaire that measures both physical and mental issues (one week recall) associated with health-related quality of life (HRQoL). Higher scores correspond to better perceived HRQoL. The SF-36 has demonstrated satisfactory reliability and validity [24] and has been suggested as the preferred instrument to measure disability in stroke patients [25].

Activities of daily living: Functional ability was assessed with the 10-item Barthel Index (BI) of Activities of Daily Living (ADL) [26]. Total scores range from 0 (ADL dependent) to 20 (ADL independent) [27]. The Norwegian version of the BI-ADL has demonstrated satisfactory validity and reliability in stroke patients [28]. Cronbach alpha for the BI-ADL was 0.92 in this sample.

Sleep quality: The patient's sleep quality was assessed with the 19-item Pittsburgh Sleep Quality Index (PSQI), which measures sleep quality, disturbance and sleep efficiency during the last month [29]. A global PSQI score ranges from 0-21; higher scores represent poorer sleep quality. Cronbach alpha for the PSQI was 0.63 in this sample.

Depressive symptoms: Depressive symptom severity was measured using the Beck Depression Inventory Version II (BDI-II) [30]. The instrument consists of 21 groups of four statements arranged by symptom severity $(0-3)$, and patients select one statement from each group. Total scores range $0-63$, with higher scores indicating more severe depressive symptoms. Total scores are categorized as follows: $0-14=$ minimal depressive symptoms, 14-19=mildly depressed, 20-28=moderately depressed, and 29-63=severely depressed range. Cronbach's $\alpha$ for the BDI-II in this study was 0.88 . BDI has been found to be an acceptable screening instrument for depression in stroke patients [31].

Other clinical variables: Patients' use of sleep medication during the last three days, their past or present illnesses and medical diagnoses were collected from their medical record.

\section{Statistical analysis}

Participants were grouped into three age groups $(<60,60-74$, and $\geq 75$ years) for the purpose of reporting sample characteristics. Descriptive statistics were used to summarize socio-demographic and clinical characteristics by age group. Differences between age groups were assessed by analysis of variance (ANOVA) for continuous variables and by Chi-square $\left(\chi^{2}\right)$ test for categorical variables. Associations between variables were assessed using Pearson correlation coefficient (r). Scatterplots were used to visualize the bivariate relationship between post-stroke fatigue (FSS-7 scores) and age. A multivariate linear regression analysis was conducted to evaluate the effect of age on post-stroke fatigue while controlling for other relevant variables. Variables correlated with fatigue $(r \geq 0.15)$ were included as covariates. Age was entered into the model first, and both linear and quadratic effects were evaluated. Other socio-demographic and clinical variables were added to the model in subsequent steps. The extent to which each step improved the model was evaluated by testing the significance of the associated change in $\mathrm{R}^{2}$. The level of significance was set at $\mathrm{p}<0.05$, and all tests were two-tailed. The data were analysed using SPSS for Windows Version 17.0 (SPSS Inc. , IL, USA).

\section{Results}

\section{Participants}

Socio-demographic and clinical characteristics for patients in each 

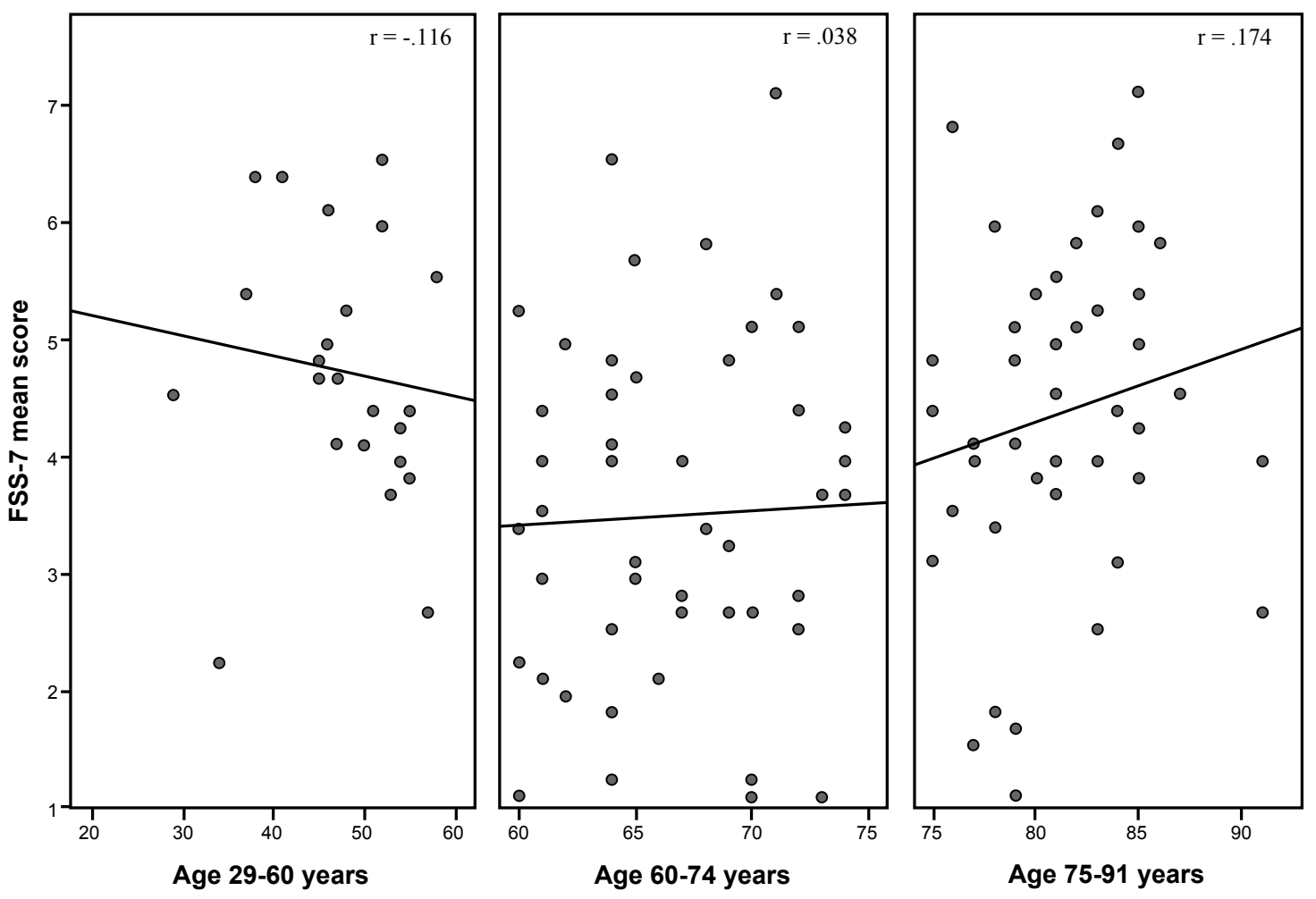

Figure 1: Scatterplot of post-stroke fatigue (FSS-7 score) by age.

age group are summarized in Table 1 . The middle age group (60-74 years) reported lower post-stroke fatigue than both the youngest $(<60$ years) and oldest ( $\geq 75$ years) age groups, which did not differ. A similar pattern was observed in the report of pre-stroke fatigue, although the group differences were not statistically significant. Not surprisingly, the three age groups also differed on several socio-demographic variables, with less likelihood of being in a paired relationship or working in the older age groups. The age groups did not differ significantly with respect to gender or education, stroke characteristics, or use of sleep medication. The oldest age group reported significantly poorer physical functioning and had significantly lower body mass index compared to the two younger age groups, which did not differ. There were subtle, non-significant differences between the groups on measures of independence in activities of daily living, sleep quality, and depressive symptoms.

A plot of post-stroke fatigue by age suggested a weak association (Figure 1). While the linear effect of age accounted for almost none of the variance, the quadratic effect accounted for a significant proportion (7.3\%) of the variance in post-stroke fatigue. The addition of a cubic term did not significantly improve the $\mathrm{R}^{2}$ or amount of explained variance in fatigue severity scores on the FSS-7.

The bivariate correlations among post-stroke fatigue and sociodemographic and clinical variables are shown in Table 2 . To evaluate the relationship between post-stroke fatigue and age while controlling for other relevant variables, a hierarchical linear regression was conducted and results are presented in Table 3. Due to missing data on the ADL and depression measures, 100 patients had complete data and were included in the regression analysis. The linear effect of age (Step 1) was not significant, but the addition of a quadratic term for age significantly improved the model's $\mathrm{R}^{2}$ (Step 2). Age was still a significant predictor of fatigue after controlling for gender and work status (Step 3 ), and after controlling for pre-stroke fatigue, physical functioning, independence with activities of daily living, sleep disturbance, and comorbid respiratory illness, but the age effect was attenuated after controlling for depressive symptoms. Depressive symptoms attenuated the effect of age on post-stroke fatigue regardless of whether any other factors were included in the model. The interaction between age and gender was not significant and was therefore not included in the final model.

The association between depressive symptoms and post-stroke fatigue was strong $(\mathrm{r}=0.468)$, with the majority $(\mathrm{n}=18,62 \%)$ of the 29 patients who reported severe post-stroke fatigue (FSS-7 $\geq 5$ ) also reporting more than minimal depressive symptoms (BDI-II scores $\geq$ 14; $\left.\chi^{2}[2]=22.0, \mathrm{p}<0.001\right)$. However, it should also be noted that more than a third $(n=11,38 \%)$ of those reporting severe fatigue reported depressive symptoms in the minimal range.

\section{Discussion}

The main focus of this study was to examine the relationship between age and fatigue among stroke survivors. Although post-stroke fatigue in the acute phase was more severe among the youngest and oldest groups in this study, age only explained a small proportion of the variance in post-stroke fatigue. The weak, curvilinear relationship between age and post-stroke fatigue evident in this sample may also explain the contradictory findings of studies on age and fatigue later in the post-stroke period. Curvilinear relationships can lead to misleading conclusions when using statistical techniques that assume linearity, particularly when evaluating relationships within restricted ranges. For example, Figure 1 might suggest a negative linear relationship if only evaluating the younger half of the sample, a positive linear relationship 
Citation: Lerdal A, Gay CL, Lee KA (2013) Curvilinear Relationship Between Age and Post-Stroke Fatigue among Patients in the Acute Phase following First-Ever Stroke. Int J Phys Med Rehabil 1: 141. doi:10.4172/2329-9096.1000141

Page 4 of 7

\begin{tabular}{|c|c|c|c|c|}
\hline & \multicolumn{3}{|c|}{ Patient Age Group } & \multirow[b]{2}{*}{ Test statistic and $p$-value } \\
\hline & $29-59$ yrs $n=23$ & $60-74$ yrs $n=49$ & $75-91$ yrs $n=43$ & \\
\hline \multicolumn{5}{|l|}{ Fatigue measures } \\
\hline Post-stroke, FSS-7 (1-7), mean (SD) & $4.6(1.1)$ & $3.4(1.5)$ & $4.3(1.4)$ & $F(2,112)=7.75, p=.001$ \\
\hline No/mild fatigue, $\mathrm{n}(\%)$ & $5(22 \%)$ & $32(65 \%)$ & $17(39 \%)$ & $x 2(2)=14.0, p=.007$ \\
\hline Moderate fatigue, $\mathrm{n}(\%)$ & $10(43 \%)$ & $9(19 \%)$ & $12(28 \%)$ & \\
\hline Severe fatigue, $\mathrm{n}(\%)$ & $8(35 \%)$ & $8(16 \%)$ & $14(33 \%)$ & \\
\hline Pre-stroke, $\mathrm{n}(\%)$ & $9(39 \%)$ & $10(20 \%)$ & $15(35 \%)$ & $x 2(2)=3.57, p=.168$ \\
\hline \multicolumn{5}{|l|}{ Socio-demographic variables } \\
\hline Age in years, mean $(\mathrm{SD})$ & $47.6(7.6)$ & $66.6(4.5)$ & $81.3(3.9)$ & $F(2,112)=334, p<.001$ \\
\hline Gender, $\mathbf{n}(\%)$ & & & & $x 2(2)=3.27, p=.195$ \\
\hline Men & $16(70 \%)$ & $31(63 \%)$ & $21(49 \%)$ & \\
\hline Women & $7(30 \%)$ & $18(37 \%)$ & $22(51 \%)$ & \\
\hline Years of formal education, $\mathrm{n}(\%)$ & & & & $x 2(2)=0.70, p=.704$ \\
\hline$<12$ years & $15(65 \%)$ & $36(73 \%)$ & $32(74 \%)$ & \\
\hline$\geq 12$ years & $8(35 \%)$ & $13(27 \%)$ & $11(26 \%)$ & \\
\hline In paired relationship, $\mathrm{n}(\%)$ & $20(87 \%)$ & $35(71 \%)$ & $21(49 \%)$ & $x 2(2)=10.8, p=.005$ \\
\hline Working, n (\%) & $17(74 \%)$ & $11(22 \%)$ & $0(0 \%)$ & $x 2(2)=44.6, p<.001$ \\
\hline \multicolumn{5}{|l|}{ Clinical variables, $\mathbf{n}(\%)$} \\
\hline Stroke type & & & & $x^{2}(2)=2.41, p=.661$ \\
\hline Infarct & $17(74 \%)$ & $41(84 \%)$ & $32(74 \%)$ & \\
\hline Haemorrhage & $1(4 \%)$ & $2(4 \%)$ & $4(9 \%)$ & \\
\hline Not detectable & $5(22 \%)$ & $6(12 \%)$ & $7(16 \%)$ & \\
\hline Stroke location ( $n=90)$ & & & & $x^{2}(2)=6.19, p=.403$ \\
\hline Right & $6(35 \%)$ & $14(34 \%)$ & $11(34 \%)$ & \\
\hline Left & $8(47 \%)$ & $14(34 \%)$ & $7(22 \%)$ & \\
\hline Bilateral & $3(18 \%)$ & $9(22 \%)$ & $8(25 \%)$ & \\
\hline Unknown & $0 \quad(0 \%)$ & $4(10 \%)$ & $6(19 \%)$ & \\
\hline Use of sleep medication & $4(17 \%)$ & $11(22 \%)$ & $16(37 \%)$ & $x 2(2)=3.87, p=.144$ \\
\hline \multicolumn{5}{|l|}{ Clinical variables, mean (SD) } \\
\hline Physical Functioning, SF-36 (1-100) & $68.9(27.6)$ & $66.3(31.6)$ & $45.0(33.8)$ & $F(2,112)=6.61, p=.002$ \\
\hline Activities of Daily Living, BI (1-20) $(n=106)$ & $17.5(4.7)$ & $18.6(3.3)$ & $16.7(4.3)$ & $F(2,103)=2.35, p=.101$ \\
\hline Sleep Quality, PSQI (0-21) (n=113) & $6.8(4.0)$ & $6.2(3.4)$ & $7.8(3.5)$ & $F(2,110)=2.40, p=.096$ \\
\hline Depression, BDI-II (0-63) (n=111) & $11.5(7.8)$ & $7.6(7.3)$ & $10.6(7.4)$ & $F(2,108)=2.77, p=.067$ \\
\hline Body Mass Index $(n=104)$ & $27.8(6.1)$ & $27.4(4.2)$ & $23.8(4.8)$ & $F(2,101)=7.15, p=.001$ \\
\hline
\end{tabular}

Note. FSS-7 = Fatigue Severity Scale 7 item version; BI = Barthel Index; PSQI = Pittsburgh Sleep Quality Index; BDI-II=Beck Depression Inventory II. Scale range in parentheses.

Table 1: Demographic and clinical characteristics by age group $(\mathrm{N}=115)$.

\begin{tabular}{|c|c|c|c|c|c|c|c|c|c|c|}
\hline & 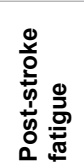 & ஓ্ & 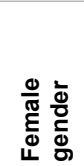 & $\begin{array}{l}\text { 능 } \\
\text { ¿े }\end{array}$ & 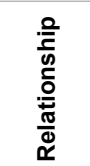 & 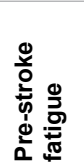 & 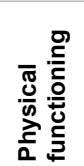 & 克 & 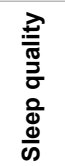 & 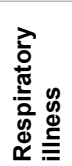 \\
\hline Age & -.030 & & & & & & & & & \\
\hline Female gender & .170 & $.189^{*}$ & & & & & & & & \\
\hline Working & .006 & $-.578^{*}$ & -.142 & & & & & & & \\
\hline In a relationship & -.105 & $-.284^{*}$ & $-.301^{*}$ & $.235^{*}$ & & & & & & \\
\hline Pre-stroke fatigue & $.425^{*}$ & -.010 & -.073 & -.012 & -.140 & & & & & \\
\hline Physical functioning & $-.410^{*}$ & $-.264^{*}$ & $-.201^{*}$ & $.264^{*}$ & $.197^{*}$ & -.079 & & & & \\
\hline $\operatorname{ADL}(n=106)$ & -.186 & -.004 & -.146 & .153 & $.249^{*}$ & .024 & $.577^{\star}$ & & & \\
\hline Sleep quality & $.211^{*}$ & .172 & $.194^{*}$ & -.122 & $-.281^{*}$ & $.192^{*}$ & $-.336^{*}$ & -.185 & & \\
\hline Respiratory illness & $.261^{*}$ & .165 & .012 & -.106 & -.059 & .152 & -.035 & -.101 & .058 & \\
\hline Depression ( $n=111)$ & $.468^{*}$ & -.050 & .109 & -.006 & -.154 & $.350^{*}$ & -.158 & -.075 & $.345^{*}$ & $.216^{*}$ \\
\hline
\end{tabular}

Note. FSS- 7 = 7 item version of the Fatigue Severity Scale; ADL = Activities of Daily Living ${ }^{*} p<.05$

Table 2: Pearson correlations between post-stroke fatigue (FSS-7) and socio-demographic and clinical variables $(\mathrm{N}=115)$.

if evaluating the older half of the sample, or no relationship at all if only linear relationships were evaluated. Several studies report more post-stroke fatigue among younger stroke survivors [14,15], but they only reported their sample's age as a descriptive mean and standard deviation. Without knowing the actual age range of the patients included and given the possibility of a curvilinear relationship between age and post-stroke fatigue, it is difficult to interpret their findings or compare their findings with ours. 


\begin{tabular}{|c|c|c|c|c|c|}
\hline Steps & Independent variables & $\beta$ & $\mathbf{p}$ & $\mathbf{R}^{2}$ & $\Delta \mathbf{R}^{2}$ \\
\hline \multirow[t]{2}{*}{1} & Age only - linear effect & & & .001 & .001 \\
\hline & Age - linear & -.030 & .766 & & \\
\hline \multirow[t]{2}{*}{2} & Age only - quadratic effect & & & .073 & $.072^{*}$ \\
\hline & $\begin{array}{l}\text { Age - linear } \\
\text { Age - quadratic }\end{array}$ & $\begin{array}{l}-2.141 \\
2.128\end{array}$ & $\begin{array}{l}.007 \\
.007\end{array}$ & & \\
\hline \multirow[t]{5}{*}{3} & Add other socio-demographic variables & & & .096 & .023 \\
\hline & Age - linear & -2.048 & .010 & & \\
\hline & Age - quadratic & 2.019 & .012 & & \\
\hline & Sex (reference=male) & 0.156 & .122 & & \\
\hline & Work status (reference=not working) & 0.024 & .843 & & \\
\hline \multirow[t]{10}{*}{4} & Add clinical variables & & & .457 & $.361^{*}$ \\
\hline & Age - linear & -1.770 & .008 & & \\
\hline & Age - quadratic & 1.606 & .015 & & \\
\hline & Sex (reference=male) & 0.144 & .081 & & \\
\hline & Work status (reference=not working) & 0.070 & .472 & & \\
\hline & Pre-stroke fatigue (reference $=$ no) & 0.348 & $<.001$ & & \\
\hline & Physical functioning (SF-36) & -0.477 & $<.001$ & & \\
\hline & ADL (Barthel Index ) & 0.174 & .092 & & \\
\hline & Sleep quality (PSQI total score) & 0.004 & .964 & & \\
\hline & Respiratory disease & 0.233 & .005 & & \\
\hline \multirow[t]{11}{*}{5} & Add depressive symptoms & & & .491 & $.034^{*}$ \\
\hline & Age - linear & -1.295 & .053 & & \\
\hline & Age - quadratic & 1.165 & .080 & & \\
\hline & Sex $($ reference=male $)$ & 0.127 & .115 & & \\
\hline & Work status (reference=not working) & 0.072 & .446 & & \\
\hline & Pre-stroke fatigue (reference=no) & 0.292 & .001 & & \\
\hline & Physical functioning (SF-36) & -0.454 & $<.001$ & & \\
\hline & ADL (Barthel Index) & 0.144 & .153 & & \\
\hline & Sleep quality (PSQI total) & -0.058 & .505 & & \\
\hline & Respiratory disease & 0.191 & .019 & & \\
\hline & Depression (BDI-II score) & 0.223 & .017 & & \\
\hline
\end{tabular}

Note. FSS-7 = Fatigue Severity Scale 7 item version; ADL = Activities of Daily Living; PSQI = Pittsburgh Sleep Quality Index; BDI-II=Beck Depression Inventory II. The model was significant $(p<.05)$ at steps 2 through 5 , but not at step 1. Test of final model: $F(10,89)=8.58, p<.001)$, adjusted $R^{2}=.434$

Table 3: Multivariate relationships between post-stroke fatigue (FSS-7) and age, controlling for other demographic and clinical variables ( $n=100)$.

Our findings suggest that fatigue in the acute phase after stroke may have different etiologies in older and younger patients and may affect them differently. A previous study of stroke survivors between 37 and 54 years of age reports that fatigue is an overwhelming experience that greatly impacts daily functioning and life [32]. In that study, patients with fatigue expressed frustration with having limited capacity to do work, engage in family and social life, and take responsibility for the family's economic situation. Their frustration may be exacerbated by the fact that fatigue is invisible compared to more external injuries and that they are of an age group in which they are expected to be most productive and capable. In one recent study, some stroke survivors reported that their fatigue had a less negative impact in their daily life as they became older [33], possibly due to reduced expectations and responsibilities. A study of fatigue in the general population showed that fatigue among older adults was related to a higher rate of comorbidity among the oldest participants [34]. This may also be a plausible explanation for the higher level of fatigue among the oldest stroke survivors in this study. Efforts to aid patients in managing their fatigue may therefore need to focus on the specific demands, as well as the co-morbid conditions, faced by stroke survivors of different ages.

Consistent with the findings of other studies of post-stroke fatigue, the effect of age in this study was quite small compared with other factors, such as pre-existing fatigue, physical functioning, and depressive symptoms. Therefore, it should not be assumed that fatigue during the acute phase after stroke is simply a function of advancing age. Furthermore, it should not be assumed that fatigue will resolve on its own, since fatigue in the acute phase is also likely to predict fatigue in the rehabilitation period and beyond [15]. Fatigue can be a significant barrier to the rehabilitation process and has been associated with both recovery outcomes and quality of life [35]. Given the importance of effectively managing fatigue, both during the acute phase and later in the post-stroke period, evidence-based interventions are needed.

The associations between post-stroke fatigue and clinical factors, such as pre-existing fatigue, physical functioning, depressive symptoms, and respiratory disease have been previously documented $[1,16,36]$, thus justifying their inclusion as covariates in the current analysis. Consistent with other studies, post-stroke fatigue had a strong association with depressive symptoms, even when controlling for other related variables, such as pre-stroke fatigue, sleep disturbance, and physical functioning. Although depressive symptoms should be evaluated among patients reporting post-stroke fatigue, more than a third of the patients reporting severe fatigue (FSS-7 $\geq 5$ ) had BDI-II scores within the normal range $(<14)$. This finding is consistent with the study by Parks and colleagues [14] in which $49 \%$ of stroke patients who reported fatigue as one of their worst symptoms, did not report clinically significant depressive symptoms. These findings confirm those of earlier studies $[37,38]$ and indicate that post-stroke fatigue can occur in the absence of depressive symptoms. It remains unclear how the co-occurrence of depression influences the impact of fatigue on rehabilitation outcomes and how interventions can best address such co-morbid conditions. 
The results of this study should be considered in light of several limitations. Data on stroke characteristics were limited to type and general location, and the small number of haemorrhagic strokes limited our ability to effectively evaluate the role of stroke type. Nonetheless, most studies that have included more detailed information on stroke characteristics have not found significant relationships between stroke characteristics and post-stroke fatigue [2,8,11,17,36,39]. Although representative of the larger population of stroke patients, this sample consisted of a relatively small number of younger patients, resulting in a fairly wide age range in the youngest age group (29 to 59 years). Given that this wide age range spans several life phases before one's retirement years, and that this group also had the highest fatigue scores, studies are needed to better identify factors associated with fatigue within this group.

\section{Conclusion}

Although post-stroke fatigue in the acute phase was more severe among the youngest and oldest groups, age only explained a small proportion of the variance in post-stroke fatigue. Although the curvilinear effect of age was statistically significant when not accounting for depressive symptoms, the effect size was small and likely has limited clinical relevance. Clinical factors, such as pre-existing fatigue, physical functioning, and particularly mood are likely more important explanations for post-stroke fatigue than age. Since fatigue may impact the patient's ability to participate in rehabilitation, clinicians should pay attention to fatigue and its co-existing factors during the acute phase. Evidence-based interventions for managing post-stroke fatigue and improving rehabilitation outcomes are warranted.

\section{Acknowledgments}

The Research Council of Norway (Grant: \# 176503) and Buskerud University College, Drammen, Norway, funded this research. This paper is a product stemming from the research project: Post-stroke Fatigue for which Dr. Hesook Suzie Kim is the project director and Drs Grethe Eilertsen, Anners Lerdal and Heidi Ormstad are the principal researchers. This project was funded by the Research Council of Norway and Buskerud University College from 2006 to 2010. We acknowledge the support and assistance provided by Research Fellow Linda N. Bakken, research assistant Gunn Pedersen and various staff members of Buskerud Hospital Trust in Drammen and Oslo University Hospital-Aker in Oslo, Norway, in carrying out this research project. AL has received funding from the RCN (Leif Eriksson Scholarship Grant \# 19256), the Norwegian Nurses Organization and the U. S. -Norway Fulbright Foundation.

\section{References}

1. Lerdal A, Bakken LN, Kouwenhoven SE, Pedersen G, Kirkevold M, et al. (2009) Poststroke fatigue-a review. J Pain Symptom Manage 38: 928-949.

2. Lynch J, Mead G, Greig C, Young A, Lewis S, et al. (2007) Fatigue after stroke: the development and evaluation of a case definition. J Psychosom Res 63: 539-544.

3. Carlsson GE, Forsberg-Wärleby G, Möller A, Blomstrand C (2007) Comparison of life satisfaction within couples one year after a partner's stroke. J Rehabil Med 39: 219-224.

4. Naess $\mathrm{H}$, Lunde L, Brogger $\mathrm{J}$ (2012) The triad of pain, fatigue and depression in ischemic stroke patients: the Bergen Stroke Study. Cerebrovasc Dis 33: 461465 .

5. Lee KA, Lentz MJ, Taylor DL, Mitchell ES, Woods NF (1994) Fatigue as a response to environmental demands in women's lives. Image J Nurs Sch 26 : $149-154$

6. Krupp LB, Alvarez LA, LaRocca NG, Scheinberg LC (1988) Fatigue in multiple sclerosis. Arch Neurol 45: 435-437.

7. Lerdal A (1998) A concept analysis of energy. Its meaning in the lives of three individuals with chronic illness. Scand J Caring Sci 12: 3-10.

8. Appelros $P$ (2006) Prevalence and predictors of pain and fatigue after stroke: a population-based study. Int J Rehabil Res 29: 329-333.
9. Choi-Kwon S, Han SW, Kwon SU, Kim JS (2005) Poststroke fatigue: characteristics and related factors. Cerebrovasc Dis 19: 84-90.

10. Naess H, Nyland HI, Thomassen L, Aarseth J, Myhr KM (2005) Fatigue at long-term follow-up in young adults with cerebral infarction. Cerebrovasc Dis 20: $245-250$

11. Schepers VP, Visser-Meily AM, Ketelaar M, Lindeman E (2006) Poststroke fatigue: course and its relation to personal and stroke-related factors. Arch Phys Med Rehabil 87: 184-188.

12. Butt Z, Lai JS, Rao D, Heinemann AW, Bill A, et al. (2013) Measurement of fatigue in cancer, stroke, and HIV using the Functional Assessment of Chronic Illness Therapy - Fatigue (FACIT-F) scale. J Psychosom Res 74: 64-68.

13. Crosby GA, Munshi S, Karat AS, Worthington E, Lincoln NB (2012) Fatigue after stroke: frequency and effect on daily life. Disabil Rehabil 34: 633-637.

14. Parks NE, Eskes GA, Gubitz GJ, Reidy Y, Christian C, et al. (2012) Fatigue impact scale demonstrates greater fatigue in younger stroke survivors. Can $\mathrm{J}$ Neurol Sci 39: 619-625.

15. Snaphaan L, van der Werf S, de Leeuw FE (2011) Time course and risk factors of post-stroke fatigue: a prospective cohort study. Eur J Neurol 18: 611-617.

16. Lerdal A, Bakken LN, Rasmussen EF, Beiermann C, Ryen S, et al. (2011) Physical impairment, depressive symptoms and pre-stroke fatigue are related to fatigue in the acute phase after stroke. Disabil Rehabil 33: 334-342

17. Glader EL, Stegmayr B, Asplund K (2002) Poststroke fatigue: a 2-year followup study of stroke patients in Sweden. Stroke 33: 1327-1333.

18. Mayo NE, Poissant L, Ahmed S, Finch L, Higgins J, et al. (2004) Incorporating the International Classification of Functioning, Disability, and Health (ICF) into an electronic health record to create indicators of function: proof of concept using the SF-12. J Am Med Inform Assoc 11: 514-522.

19. Park JY, Chun MH, Kang SH, Lee JA, Kim BR, et al. (2009) Functional outcome in poststroke patients with or without fatigue. Am J Phys Med Rehabil 88: 554558.

20. World Health Organization. International Classification of Diseases (ICD).

21. Scandinavian Stroke Study (1985) Multicenter trial of hemodilution in ischemic stroke--background and study protocol. Scandinavian Stroke Study Group. Stroke 16: 885-890.

22. Krupp LB, LaRocca NG, Muir-Nash J, Steinberg AD (1989) The fatigue severity scale. Application to patients with multiple sclerosis and systemic lupus erythematosus. Arch Neurol 46: 1121-1123.

23. Lerdal A, Kottorp A (2011) Psychometric properties of the Fatigue Severity Scale-Rasch analyses of individual responses in a Norwegian stroke cohort. Int J Nurs Stud 48: 1258-1265.

24. Newnham EA, Harwood KE, Page AC (2007) Evaluating the clinical significance of responses by psychiatric inpatients to the mental health subscales of the SF36. J Affect Disord 98: 91-97.

25. Weimar C, Kurth T, Kraywinkel K, Wagner M, Busse O, et al. (2002) Assessment of functioning and disability after ischemic stroke. Stroke 33: 2053-2059.

26. Mahoney FI, Barthel DW (1965) Functional Evaluation: The Barthel Index. Md State Med J 14: 61-65.

27. Wade DT, Collin C (1988) The Barthel ADL Index: a standard measure of physical disability? Int Disabil Stud 10: 64-67.

28. Laake K, Laake P, Ranhoff AH, Sveen U, Wyller TB, et al. (1995) The Barthe $A D L$ index: factor structure depends upon the category of patient. Age Ageing 24: 393-397.

29. Buysse DJ, Reynolds CF 3rd, Monk TH, Berman SR, Kupfer DJ (1989) The Pittsburgh Sleep Quality Index: a new instrument for psychiatric practice and research. Psychiatry Res 28: 193-213.

30. Beck AT, Steer RA, Brown GK (1996) BDI-II, Beck depression inventory manual. 2nd ed. San Antonio, Tex: Psychological Corp.

31. Aben I, Verhey F, Lousberg R, Lodder J, Honig A (2002) Validity of the beck depression inventory, hospital anxiety and depression scale, SCL-90, and hamilton depression rating scale as screening instruments for depression in stroke patients. Psychosomatics 43: 386-393.

32. Röding J, Lindström B, Malm J, Ohman A (2003) Frustrated and invisible-younger stroke patients' experiences of the rehabilitation process. Disabil Rehabil 25: 867-874. 
Citation: Lerdal A, Gay CL, Lee KA (2013) Curvilinear Relationship Between Age and Post-Stroke Fatigue among Patients in the Acute Phase following First-Ever Stroke. Int J Phys Med Rehabil 1: 141. doi:10.4172/2329-9096.1000141

33. Kirkevold M, Christensen D, Andersen G, Johansen SP, Harder I (2012) Fatigue after stroke: manifestations and strategies. Disabil Rehabil 34: 665-670.

34. Lerdal A, Wahl A, Rustøen T, Hanestad BR, Moum T (2005) Fatigue in the general population: a translation and test of the psychometric properties of the Norwegian version of the fatigue severity scale. Scand J Public Health 33: 123130.

35. van de Port IG, Kwakkel G, Schepers VP, Heinemans CT, Lindeman E (2007) Is fatigue an independent factor associated with activities of daily living, instrumental activities of daily living and health-related quality of life in chronic stroke? Cerebrovasc Dis 23: 40-45.
36. Radman N, Staub F, Aboulafia-Brakha T, Berney A, Bogousslavsky J, et al. (2012) Poststroke fatigue following minor infarcts: a prospective study. Neurology 79: 1422-1427.

37. Ingles JL, Eskes GA, Phillips SJ (1999) Fatigue after stroke. Arch Phys Med Rehabil 80: 173-178.

38. van der Werf SP, van den Broek HL, Anten HW, Bleijenberg G (2001) Experience of severe fatigue long after stroke and its relation to depressive symptoms and disease characteristics. Eur Neurol 45: 28-33.

39. Carlsson GE, Möller A, Blomstrand C (2003) Consequences of mild stroke in persons $<75$ years - a 1 -year follow up. Cerebrovasc Dis 16: 383-388.
Citation: Lerdal A, Gay CL, Lee KA (2013) Curvilinear Relationship Between Age and Post-Stroke Fatigue among Patients in the Acute Phase following FirstEver Stroke. Int J Phys Med Rehabil 1: 141. doi:10.4172/2329-9096.1000141
Submit your next manuscript and get advantages of OMICS Group submissions

Unique features:

User friendly/feasible website-translation of your paper to 50 world's leading languages Audio Version of published paper

Digital articles to share and explore

Special features:

- 250 Open Access Journal

- 20,000 editorial team

21 days rapid review process

- Quality and quick editorial, review and publication processing

- Indexing at PubMed (partial), Scopus, EBSCO, Index Copernicus and Google Scholar etc

- Sharing Option: Social Networking Enabled

- Authors, Reviewers and Editors rewarded with online Scientific Credits

- Better discount for your subsequent articles

Submit your manuscript at: http://www.omicsonline.org/submission/ 